\title{
PONTIAC FEVER OUTBREAK ASSOCIATED WITH A SPA-POOL, UNITED KINGDOM, APRIL 2008
}

\author{
A Modi (a.modi@nhs.net) ${ }^{1}$, J Gardner², L Lighton ${ }^{1}$, N Coetzee $^{3}$ \\ 1. Health Protection Agency, Greater Manchester, United Kingdom \\ 2. Stockport National Health Service Foundation Trust, Greater Manchester, United Kingdom \\ 3. Health Protection Agency, West Midlands North, United Kingdom
}

On 16 April 2008, public health authorities in North West England were notified of six suspected cases of non-pulmonary legionellosis, five of whom were admitted to three different hospitals and one seen by a general practitioner. These cases presented with influenza-like symptoms: fever, headache, and muscle pain, with or without nausea. They were part of a group of seven women who had spent the weekend of 11-13 April at a residential leisure resort where they were using a spa pool (otherwise known as Jacuzzi or whirlpool).

\section{Investigation}

The cases were questioned regarding exposure histories and common risk factors for legionellosis. Urinary legionella antigen and twinned acute and convalescent sera were tested in all six cases. The leisure resort was inspected; maintenance records reviewed and water samples taken.

Cases were defined as follows:

- Confirmed case: Influenza-like illness without evidence of pneumonia and urine antigen positive for Legionella pneumophila and/or significant rise in titre for L. pneumophila antibodies and onset within 120 hours of visiting the resort between 11 and 13 April 2008.

- Probable case: Influenza-like illness without evidence of pneumonia and onset within 120 hours of visiting the resort between 11 and 13 April 2008.

\section{Descriptive epidemiology}

The leisure resort comprised three separate cottages and an indoor area with swimming pool, sauna, showers and a spa pool. The party of seven used the wet side facilities on 11 and 12 April and returned home on 13 April. All seven women used the spa and swimming pool but only five used the sauna. All used the showers at the indoor pool area and in their respective cottages.

Six of the seven women (age range 24 to 37 years) started feeling unwell between the evening of 13 April and morning of 14 April (see Figure) and reported lethargy, influenza-like symptoms, fever with shivers, muscle pain, back pain, pleuritic chest pain on inspiration, dry cough and breathlessness. The acute symptoms lasted for at least five days for all six women and one of them complained of feeling run down for a further week.
The owner of the resort who conducted the swimming pool and spa pool maintenance and was therefore exposed to the wet side facilities, reported influenza-like symptoms starting on 14 April and lasting one day (Figure). His family members had not been exposed to the wet side areas and were unaffected. The resort had been closed over winter and re-opened on 29 February 2008. All 19 guests who had stayed in the resort between 28 February and 10 April 2008 were contacted and it was ascertained that they had not experienced influenza-like symptoms or any serious illness.

\section{Environmental investigation}

The company contracted for the maintenance of water and swimming pool had conducted a site visit on 10 April and reported residual chlorine levels of $0 \mathrm{mg} / \mathrm{L}$ in the spa pool and $1 \mathrm{mg} / \mathrm{L}$ in the swimming pool. The company noted that the spa pool's automatic chlorine-dosing pump was not in working order and needed replacement. As an interim measure they advised daily hyperchlorination shock treatment of the spa pool, which the owner reported to have carried out. The resort did not keep a record of daily $\mathrm{pH}$ and residual chlorine levels. On 15 and 16 April, public health inspectors took 18 water samples for microbiological culture from the main swimming pool, spa pool and balance tank, showers and from water systems and taps in each of the three cottages.

F I G U R E

Cluster of Legionella pneumophila infections, by day of onset of symptoms, United Kingdom, April $2008(n=7)$

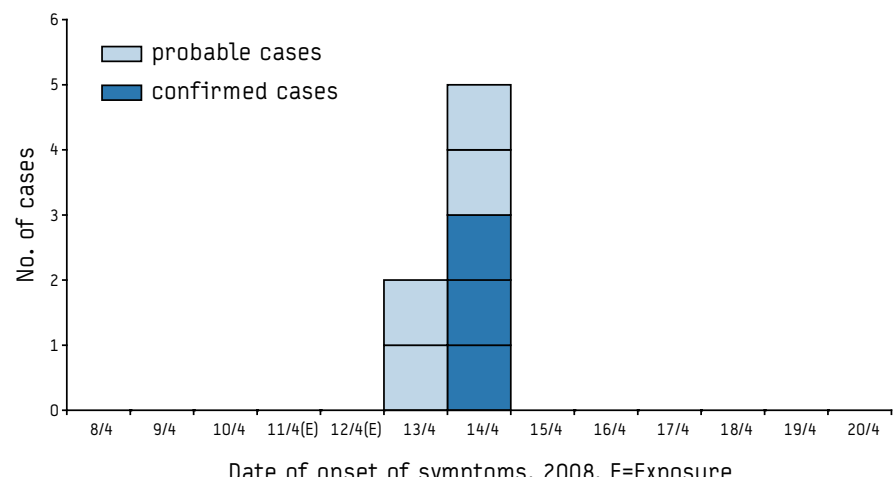




\section{Laboratory results}

Three of the party members were confirmed as Pontiac fever cases (two with urinary antigen to L. pneumophila serogroup 1 (mAb2) of whom one seroconverted, and one who was negative for urinary antigen but seroconverted).

Serological tests were carried out on three cases admitted to the same hospital for influenza A and B virus, respiratory syncytial virus, Mycoplasma pneumoniae, Chlamydia sp., Coxiella burnetii and adenovirus, all of which were non-reactive. In addition, polymerase chain reaction for influenza $A$ and $B$ virus and $L$. pneumophila was carried out on throat swabs, which were also negative.

One water sample from the spa pool balance tank cultured positive for Legionella spp (not L. pneumophila) at the minimal detectable level (1.0 X $102 \mathrm{cfu} / \mathrm{L})$.

\section{Control measures}

Four of the cases were prescribed macrolide antibiotics on presentation, three clarithromycin and one erythromycin on 15 April, and one had been treated with trimethoprim. The clinicians treating them were informed on 17 April of the link between cases, and all cases received a course of macrolide antibiotics (either clarithromycin or erythromycin).

The leisure resort complex was closed on 14 April and remained so until environmental samples were confirmed negative for legionella and the public health authorities were satisfied that remedial and maintenance measures had been implemented.

\section{Discussion and conclusion}

This point source outbreak involved three confirmed and four probable cases of Pontiac fever linked to the use of an inadequately maintained spa pool. It is likely that hyperchlorination of the spa pool shortly before the taking of water samples limited the ability to isolate L. pneumophila. Half of all reported Pontiac fever outbreaks have been linked to spa pool exposure [1,2]. Other outbreaks of legionellosis have been linked to poor maintenance of spas and guidelines have been formulated for their proper maintenance [3-6].

Seven out of eight exposed became ill, corresponding to an attack rate of $88 \%$, which is comparable with other outbreaks. The median incubation period was estimated to be 64 hours with a range from 52 to 68 hours. The severity of symptoms in this outbreak was significant enough to result in hospital admissions for five of the seven cases and all cases received antibiotics. Cases were symptomatic for around seven days with subsequent complaints of feeling run-down. Pontiac fever was confirmed by urinary antigen testing within the first week and seroconversion in the third and fourth week. Previous reports have shown variable sensitivity of these tests and our experience was the same [1,2,7,8]. Although culture is considered the gold standard, it was not possible in this case due to the lack of sputum samples $[1,8]$.

The outbreak highlights the importance of ongoing vigilance regarding the proper maintenance of the water in spa pool facilities. Pontiac fever can resemble other diseases, and existing tests show very low sensitivity in confirming the diagnosis in the absence of sputum.

\section{Acknowledgements}

We are grateful for the support received from the local environmental health department, the Health Protection Agency laboratories and the Atypical Pneumonia Unit at Centre for Infections, Colindale. We are also grateful to staff at the three hospitals and the four GP surgeries for their help.

\section{References}

1. Huhn G, Adam B, Ruden R, Hilliard L, Kirkpatrick P, Todd J, et al. Outbreak of Travel-Related Pontiac Fever among Hotel Guests Illustrating the Need for Better Diagnostic Tests. J Travel Med;12(4):173-9.

2. Edelstein P. Urine Antigen Tests Positive for Pontiac Fever: Implications for Diagnosis and Pathogenesis. Clin Infect Dis. 2007;44(2):229-31.

3. Reynolds F, McCann R, Franklin N, Chaloner J, Kirkpatrick A, Petrovic M. Swinging clubs as a potential source of Legionella infection: A case study. $J$ Environ Health. 2007;6(1). Available from: http://www.cieh.org/JEHR/swinging clubs_legionella.html

4. de Jong B, Allestam G, Knauth SB. Legionella infections from a private whirlpool in Sweden. Euro Surveill. 2004;8(21):pii=2472. Available from: http:// www.eurosurveillance.org/ViewArticle.aspx?ArticleId=2472

5. Den Boer JW, Yzerman EP, Schellekens J, Lettinga KD, Boshuizen HC, Van Steenbergen JE, et al. A Large Outbreak of Legionnaires' Disease at a Flower Show, the Netherlands, 1999. Emerg Infect Dis. 2002;8(1):37-43. Available from: http://www.cdc.gov/ncidod/eid/vol8no1/01-0176.htm

6. Editorial team. Guidelines for reducing legionella risk associated with using spa baths from the UK Health and Safety Executive. Euro Surveill. 2003;7(27):pii=2249. Available from: http://www.eurosurveillance.org/ ViewArticle.aspx?ArticleId=2249

7. Kawano K, Okada M, Kura F, Amemura-Maekawa J, Watanabe H. Largest outbreak of legionellosis associated with spa baths: comparison of diagnostic tests. Kansenshogaku Zasshi. 2007;81(2):173-82. [In Japanese].

8. Diederen BMW. Legionella spp. and Legionnaires' disease. J Infect. 2008;56(1);1-12.

This article was published on 24 July 2008

Citation style for this article: Modi A, Gardner J, Lighton L, Coetzee N. Pontiac fever outbreak associated with a spa-pool, United Kingdom, April 2008. Euro Surveill. 2008;13(30):pii=18934. Available online: http://www.eurosurveillance.org/ViewArticle. aspx?ArticleId $=18934$ 